\title{
Origin of brines and modern water circulation contribution to Qarhan salt lake in Qaidam basin, Tibetan plateau
}

\author{
Yong Xiao ${ }^{1, *}$, Qichen Hao ${ }^{2}$, Yinfei Luo ${ }^{3,5}$, Shengbin Wang ${ }^{3}$, Xueya Dang ${ }^{4}$, Jingli Shao ${ }^{5}$ and \\ Linxian Huang ${ }^{6}$ \\ ${ }^{1}$ Faculty of Geosciences and Environmental Engineering, Southwest Jiaotong University, Chengdu \\ 611756, China \\ ${ }^{2}$ Institute of Hydrogeology and Environmental Geology, Chinese Academy of Geological Science, \\ Shijiazhuang 050061, China \\ ${ }^{3}$ Bureau of Qinghai Environmental Geological Prospecting, Xining 810007, China \\ ${ }^{4}$ Xi'an Center of Geological Survey, China Geological Survey, Xi'an 710054, China \\ ${ }^{5}$ School of Water Resources and Environment, China University of Geosciences (Beijing), Beijing \\ 100083, China \\ ${ }^{6}$ School of Water Conservancy and Environment, University of Jinan, Jinan 250022, China
}

\begin{abstract}
Lake Qarhan is the largest salt lake and potassium salt resource mining base in china. Understanding the origin of brines and the contribution of modern water circulation is extremely important to the sustainable development of the salt lake. Comprehensive tools including isotope, hydrochemistry and numerical simulation had been performed. Results suggest that brine groundwater in the salt lake area is the result of ancient brines migrated from the western Qaidam Basin due to the uplift of the western basin in the geological past. Shallow phreatic aquifers in the salt lake area are also recharged by the modern surface water in the flood period. The contribution of modern groundwater circulation to the salt lake area is very limited with only $3 \%$ of the total quantity of groundwater discharge for the watershed.
\end{abstract}

\section{Introduction}

The Qaidam basin, the largest closed basin of Tibetan Plateau, has the largest number of salt lakes, salt playas and types of salt deposits in China. Lake Qarhan, located in the basin centre (Fig. 1), is the largest salt lake in China. This lake is rich in potassium mineralization, and accompanied by various minerals containing magnesium, sodium, lithium, boron and iodine. Understanding the origin of the brines and the role of modern water circulation is extremely important for sustainable exploitation of salt lake minerals resources.

The present study uses isotopic tools to develop insight into the origin of brines in the Qarhan salt lake area. A two-dimensional groundwater flow numerical simulation was also

\footnotetext{
${ }^{*}$ Corresponding author. E-mail address: xiaoyong@swjtu.edu.cn
} 
performed to assess the contribution of modern water circulation to the salt lake. This study provides insights into the origin, recharge environment of brines in Qarhan salt lake area, as well as the contribution of modern water circulation to the salt lake.

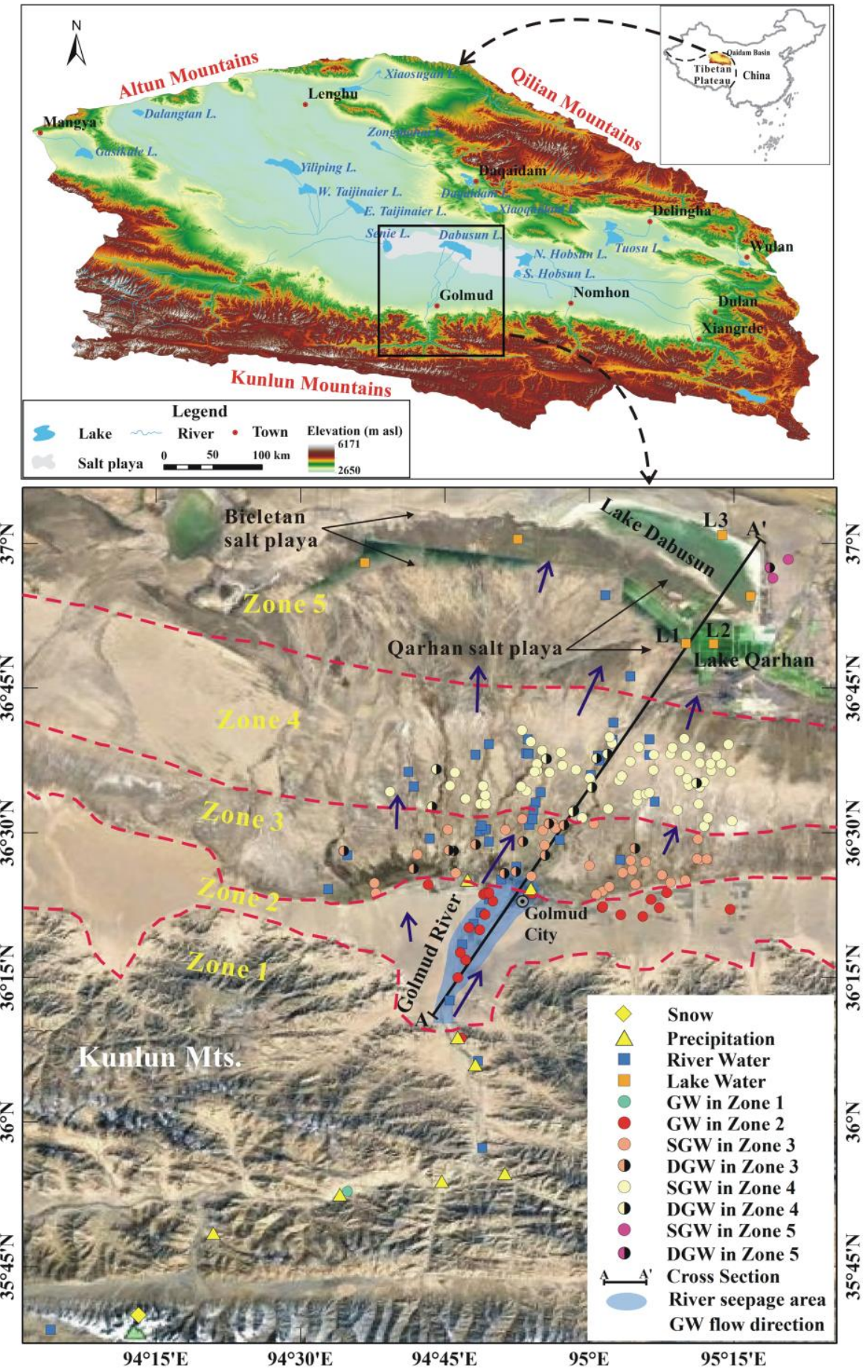

Fig. 1. Location of the study area and sampling sites in western China. 


\section{Materials and methods}

A total of 228 water samples, including 180 groundwater samples (shallow groundwater (SGW) and deep confined groundwater (DGW)) and 48 surface water samples (42 river water and 6 lake water samples) (Fig. 1), were collected from the Golmud watershed, Qaidam basin for tritium and radiocarbon dating, and stable oxygen and hydrogen isotopes analyses. In addition, one snow (snowmelt water) sample, 8 precipitation samples (Fig. 1) and 90 brine water samples (groundwater) with hydrogen and oxygen stable isotopic values were collected from the China stable isotope geochemistry database (http://210.73.59.163/isogeochem/). These brine waters were sampled from the Qarhan salt playa and Bieletan salt playa, but their detailed locations are not known.

To reveal the contribution of modern water circulation to the salt lake, a twodimensional groundwater flow numerical simulation was performed along the main direction of groundwater flow (section A-A') in the Golmud watershed (Fig. 1). TOUGH2 software was selected to construct the model and perform the modeling. An irregular discretization was conducted vertically to capture the variation of the water table near the ground surface and also implement the efficient simulation, and a newly developed evaporation modeling method by Hao et al. [1] has been used in the model.

\section{The provenance of brine waters}

The $\delta \mathrm{D}$ and $\delta^{18} \mathrm{O}$ isotope analysis results of different water bodies are shown in relation to the Global Meteoric Water Line (GMWL), Golmud Watershed Local Meteoric Water Line (LMWL) [2] and Golmud Watershed Local Evaporation Line (LEL) on Fig. 2. Most surface water and groundwater samples from the study area plot close to the GMWL and LMWL, indicating a meteoric origin. As most of the yearly precipitation occurs in the Kunlun mountainous area of the basin and is less than $50 \mathrm{~mm} / \mathrm{yr}$ [3], surface water and groundwater in the study area mainly originate from precipitation and snowmelt in the mountainous areas. River water and groundwater in the mountainous areas (Zone 1) have very similar stable water isotopic values as precipitation and snowmelt in the Kunlun mountainous area (Zone 1), indicating a strong recharge relationship. Lake waters sampled from the low-lying depression (Zone 5) have the most enriched stable water isotope values, suggesting strong evaporative controls.

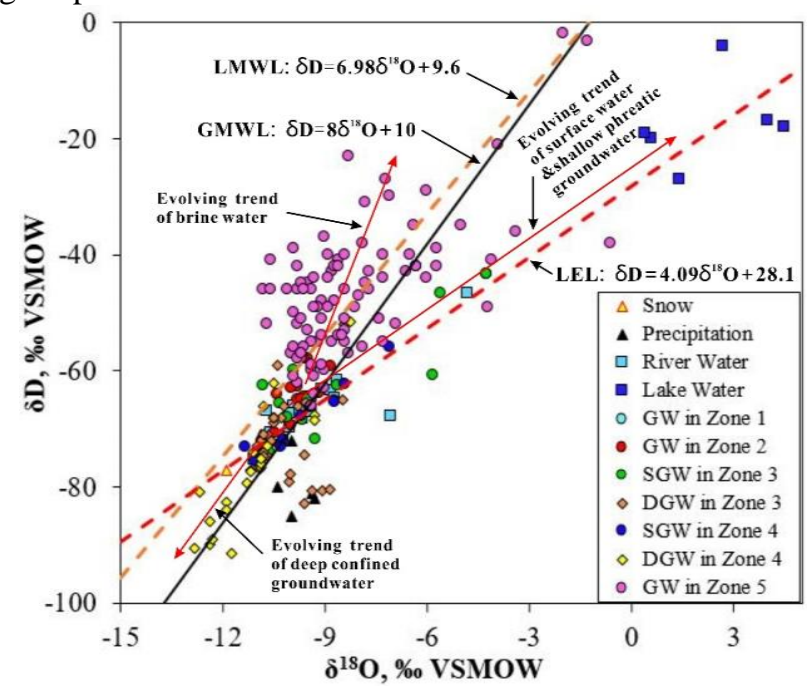

Fig. 2. $\delta^{18} \mathrm{O}$ vs. $\delta \mathrm{D}$ diagram of precipitation, surface water and groundwater, Qaidam basin, China. 
The $\delta \mathrm{D}$ and $\delta^{18} \mathrm{O}$ values of SGW and DGW demonstrate variations in their trends along the groundwater flow path. SGW shows a gradual positive enrichment trend in heavy isotopes along the LEL (Fig. 2), implying the influence of evaporation. The high ${ }^{3} \mathrm{H}$ values of SGW in Zone 3 and Zone 4, which range from 12.1 to 25.7 TU and from 14.4 to 17.5 $\mathrm{TU}$, respectively, with mean values of 21.1 TU and 16.0 TU, suggest that SGW in these two zones are modern water or mixtures with modern water. DGW in the overflow zone (Zone 3) and the middle-lower stream area (Zone 4) are observed to have a completely opposite evolving trend, showing that the $\delta \mathrm{D}$ and $\delta^{18} \mathrm{O}$ values become more depleted along the groundwater path (Fig. 2). According to the ${ }^{14} \mathrm{C}$ groundwater age, the DGW in Zone 3 and Zone 4 was recharged from 2,030 years B.P. to more than 20,090 years B.P [4]. (Holocene to late Pleistocene), which was a period in which the climate changed from cold and wet condition $(30,000$ years B.P. to 17,000 years B.P.) to warm and dry condition $\left(14,000\right.$ years B.P. to present) [5]. Consequently, DGW with depleted $\delta \mathrm{D}$ and $\delta^{18} \mathrm{O}$ is recharged by paleo water under a colder climate relative to the present. Groundwaters in the low-lying depression area (Zone 5), regardless of sampling depth, are all brines with TDS values more than $100,000 \mathrm{mg} / \mathrm{L}$ and more than 20,000 years' in age deduced by the ${ }^{14} \mathrm{C}$ values of DGW in Zone 4. While SGW was observed to have high ${ }^{3} \mathrm{H}$ content (18.9 TU), due to the addition and mixing from the leakage of modern surface water recharge. As shown in Fig.2, all groundwaters in the basin center are relatively enriched in $\delta \mathrm{D}$ and $\delta^{18} \mathrm{O}$ values in contrast with modern water and DGW in the upstream areas, but deviate away the LEL towards the left. Given the tectonic activity and depocenter migration within the Qaidam Basin over its geological history [6], groundwaters in the central depression area (Zone 5) are paleo-brines that migrated from the western Qaidam Basin due to uplift.

\section{Contribution of modern water circulation}

According to the 2-D numerical groundwater flow modeling, three groundwater flow systems including local, intermediated and regional were identified in the watershed (Fig.3). The local groundwater flow system occurs in the shallow part of the alluvial fan (Zone 2) and overflow zone (Zone 3) with the deepest circulation depth within $250 \mathrm{~m}$ of surface. The intermediate flow system occurs below the local system and is recharged by river water seepage near the upper part of the alluvial fan. Groundwater flows towards the north and reaches its deepest at $600 \mathrm{~m}$ in the middle part of the alluvial fan (Zone 2). The regional groundwater flow system occurs under the intermediate system and is recharged in the upper part of alluvial fan by river water seepage and lateral flow from the mountains and discharge at the basin center impacted by evaporation in the terminal lakes. The quantity of water cycled by the local, intermediate and regional systems estimated by the model accounts for $83 \%, 14 \%$ and $3 \%$ of the total groundwater volume in the watershed, respectively.

\section{Conclusions}

Waters in the basin originate from precipitation and melt water in the mountainous areas. Groundwater in the salt lake area (low-lying depression) is ancient brines that migrated from the western Qaidam Basin due to the uplift of western basin in the geological past. Shallow phreatic aquifers in the salt lake area are also recharged by modern surface waters during periods of flooding. Only $3 \%$ of the of the modern groundwater circulation system discharges at the basin center based on modeling calculations. Thus, the contribution of modern groundwater circulation to the salt lakes is very limited. 


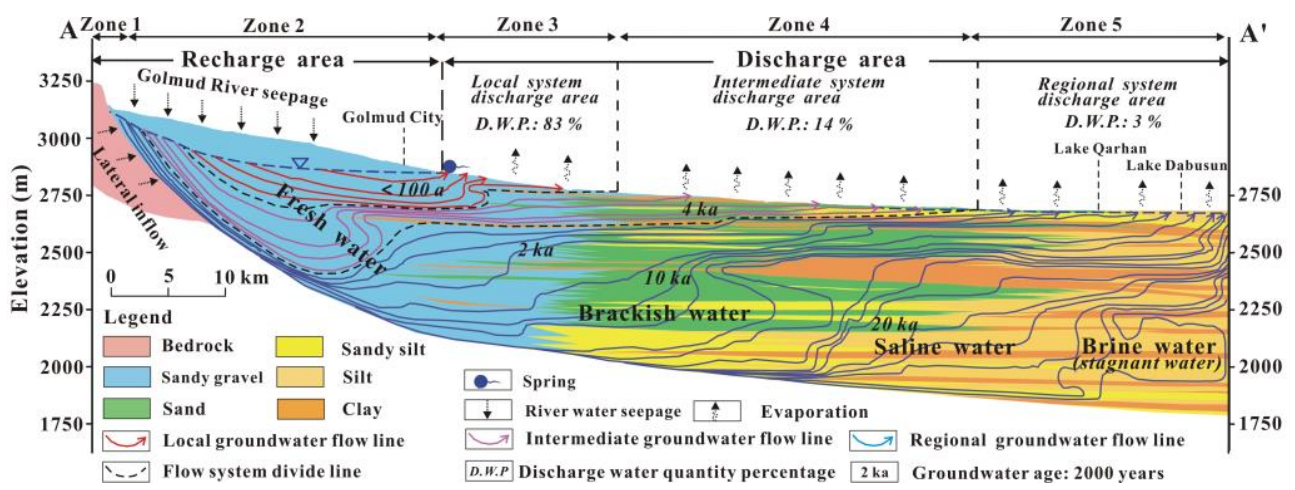

Fig. 3. Conceptual model of groundwater flow and hydrochemical evolution in the Golmud watershed, Qaidam Basin, China.

This work was supported by the Fundamental Research Funds for the Central Universities (2682019CX14), the Natural Science Foundation of China [41702282], the National Key R\&D Program of China [2017YFC0406106] and the China Geological Survey [DD20160291].

\section{References}

1. Q.C. Hao, J.L. Shao, Y.L. Cui, Q.L. Zhang, Journal of Groundwater Science and Engineering, 4, 26-34 (2016).

2. Y.H. Wang, Chang'an University, Xi'an, China, (2014).

3. Y. Xiao, J.L. Shao, Y.L. Cui, G. Zhang, Q.L. Zhang. Journal of Earth System Science, 126, 1-15 (2017).

4. Y. Xiao, J.L. Shao, S.K. Frape, Y.L. Cui, X.Y. Dang, S.B. Wang, Y.H. Ji, Hydrology \& Earth System Sciences, 22, 4381-4400 (2018).

5. M. Zhang, Y.X. Chen, S.L. Yin, J.C. Zhang, C.C. Li, G.N. Liu, Arid Land Geography, 34, 890-903 (2011).

6. K.Z. Chen, J.M. Bowler, Palaeogeography Palaeoclimatology Palaeoecology, 54, 87104 (1986). 